
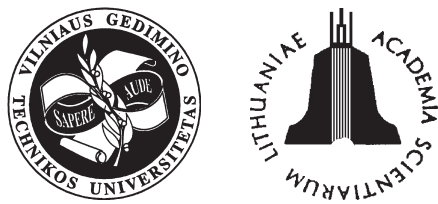

\title{
A PROCESSUAL METHOD, THE METHOD HELPING TO MANAGE THE QUALITY OF TRANSPORT SERVICES
}

\author{
Aleksandr Pankov', Igor Petuhov², Vladimir Shestakov ${ }^{3}$ \\ ${ }^{1}$ Transport and Communication Institute, Lomonosov 1, LV-1019 Riga, Latvia, E-mail:pankov@tsi.lv; \\ 2,3Riga Technical University, Kalku 1, LV-1013 Riga, Latvia,E-mail: avia1@inbox.lv \\ Received 2 April 2005, accepted 30 September 2005
}

\begin{abstract}
Transportation organization is inspected as three ground processes and each of these processes has dynamic indices. The connection of undynamics between these indices is the foundation for managing, the acception of managment decision and for a big number of other actions. There are some results of the aprobation of this method.
\end{abstract}

Keywords: process, quality, safety, model, transportation production, analysis, organization.

\section{Introduction}

All kinds of actions in every organization can be inspected as a technological process. There these processes work together and the level of work is very complicated. These actions form a system or a process sieve. This method is included in the international law ISO-9000 [1].

There you can read about the processes which are groups of goals and each of them is interconnected. There is only one way how to solve them. The result action of solving these exercises and problems is forming and creating of valuables for consumers. These valuables must satisfy all consumer's needs. We can represent every process like totaly coordinated points (work object, resource, organization items), functions (activity) and adventures. Various technological processes are composed by diferent actions. That is why some operations and actions which get something on input and modify it on output can be inspected as a process. Exercise integration desn't negate functions of needful specialization which represents competiviness and special goals for solving neccesary problems. There is an aproach to the organization work and actions which we can show like a process. This process connects the organization's abilities and estabilishment. It lets us understand organization work intercomunication and cooperation with other organizations. The approach to direct questions is based on the process which we can call processuality [2].

\section{Fixation of goals}

Let's use the method of questions and problems for transportation services managment. Transportation services can be represented like a blast and factor system which is totally in a process. The result of transportation company's activity is the quantity of carried passengers, cargoes and the quantity of transportation work. These are final results of organization's work. Transportation services are characterised by quality levels which we can clasify into three grades:

- technical,

- economical,

- social.

Socially remarkable criteria for transportation companies are social criteria of quality:

- safety of fly,

- level of boon quality,

- ecological influence to nature,

- regularity of transportation movement,

- rapidity of transportation.

Each of them represents a testiomantial complex of all transportation system, transportation organization, vehicles.

The safety of the movement is a complex of transport characteristics which characterises its posibility to realise transport services without dangerous situations from cargos for people's health. In this process $\mathrm{K}_{1}$ represents a number of dangerous situations in one flight (in one hour, etc.) [3]. $\mathrm{K}_{2}$ is the level of 
influence to nature and ecology.

Service conditions of the transportation are marked by consumer's demand $-\mathrm{K}_{3}$. In the first scheme (Fig 1) you can see the connection between quantity and quality criteria in transport organization's work. Has we can see in the scheme all of them are connected and they depend on the same factors. These factors can be distributed into two groups:

- materialistic factors,

- social factors.

The model which you can see in Fig 1 could be represened like three processes. The result of these processes is the materialistic and social factors which are changing all the time. These processes are:

1. Transmigration of investment. It is happening under the pressure of science and pressure of technologies. They tend to improve and create new transportation vehicles, amortization of ground funds, modernization of vehicles, transport value, number of vehicles in organization.

2. Operation process is represented by the dynamics of exploatation materials and dynamic value

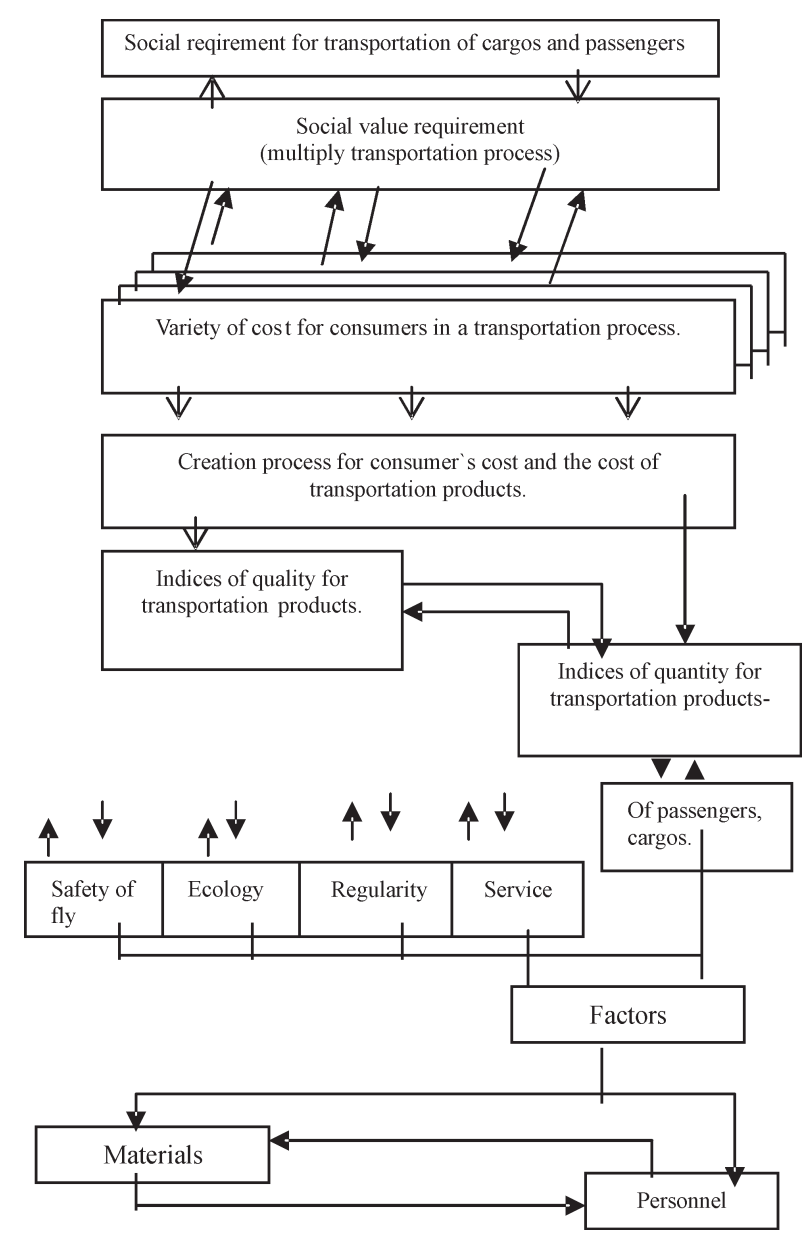

Fig 1. Interaction between quality indices and economical chategories for manufacturing of transportation products (oil, amortization) of vehicles and other equipment.

3. Process where we can get final results. We can get the results about airline work $(\mathrm{t} / \mathrm{km}$, quantity of passenger's carried) and dynamic rechange of transportation services quality (safety of movement, level of service, ecological indices).

The interaction of these processes results in different and useful final results. These results can be shown in quality and quantity indices.

We will look at the dynamic recension of indices which represent the process in the final period of time:

- D1 - Dynamic recension of useful final results(in this indice recension is shown by dynamic indice changes in one important period: indices of organization's work quality like $\mathrm{W}_{\mathrm{tkm}}$ - tonne kilometers; $\mathrm{K}_{1}$ - level of the safe fly; ecology $-\mathrm{K}_{2} ; \mathrm{K}_{3}$, e. etc., and quantity indices which we can call as $\mathrm{a}_{1} ; \mathrm{a}_{2} ; \mathrm{a}_{3} \ldots$ an.

- D2 - dynamic recension of materialistic factor variety (materialistic-technological base). It is shown by dynamic recension in investment and in ground manufacturing fund.

- D3 - dynamic recension of factors in operation period (variety of nature and climate, improvement of technique, transport and equipment, factors of manufacture organisation).

These three indices can be in one of these dynamic interaction varieties;
1. $\mathrm{D} 1>\mathrm{D} 2>\mathrm{D} 3$
2. $\mathrm{D} 2>\mathrm{D} 1>\mathrm{D} 3$
4. $\mathrm{D} 1>\mathrm{D} 3>\mathrm{D} 2$
3. D2 > D3 > D1
5. D3 $>\mathrm{D} 2>\mathrm{D} 1$

Goals of managing are to show the connection between D1; D2; D3 which will give the best level of solution for the enterprise and society aims.

Lets look at these interaction varieties. In case when $\mathrm{D} 3>\mathrm{D} 2$ the dynamic recension of operation cost forms the situation when capital investment in the organization infrastructure is rising. It tells us that the cause of capital investment is not exploitation cost savings. And companies exploatation work doesn't affect the effective use of capital investment. After that we can see that connection D3 $>$ D2 doesn't give enough good result for people needs. It will be better if we use connection D2 $>$ DA3. Exploitation costs are determined by dynamic recension of investment. Other costs are decreasing.

Useful final results are necessary for society when other costs are rising. $\left(\mathrm{W}_{\mathrm{tkm}} ; \mathrm{K}_{1} ; \mathrm{K}_{2} ; \mathrm{K}_{3}, \ldots, \mathrm{a}_{1} ; \mathrm{a}_{2} ; \mathrm{a}_{3}\right.$; ....; an). This action must give recension of D2; D3.

The reason of that is the necessity to make bigger profit from work in manufacturies and quality of transportation services.

After all we can see that the most efective connection between indices and wants of society is: 
D1 $>$ D2 $>$ D 3 .

If the company works according to the proccess the indices will rise like it is shown in indices cooperation. This is the foundation for transportation companies effective work and good final results too. And we can note that cooperation number 2 is the normative for transportation organization's developement.

In reality the level of real quantity is equal to a well formed level of quantity. It is the organization's work when it is dividing resources with the aim to satisfy a greater number of society's needs.

The main aim for most organizations in the whole market is that the increased speed of quality characteristics should form the increasing speed of work volume. In this situation the cost of exploitation and investment should be lower than characteristics of quality and work volume. Relation like that can exist only if there is the policy of law and investment. The main aim of structural politics is that the dynamics of capital investment should be equal to the dynamics of last results. If recension speed of quality indices is decreasing then you should analyse that situation and find the reason of that. The reason of decrease can be avert by capital investment and investment should be made in that area which is the reason of decreasing.

\section{Model of transportation products and their con- nection with the results of existing organization}

In the main this connection can be shown like that:

$\mathrm{W}_{\text {tkm ef }}=\mathrm{f}\left(\mathrm{W}_{\mathrm{tkm}} ; \mathrm{K}_{1} ; \mathrm{K}_{2} ; \mathrm{K}_{3}, \ldots ., \mathrm{a}_{1} ; \mathrm{a}_{2} ; \mathrm{a}_{3} ; \ldots . ;\right.$ an $)$

$\mathrm{W}_{\mathrm{tkm}}$ - cost of transportation production for consumers.

$\mathrm{K}_{1} ; \mathrm{K}_{2} ; \mathrm{K}_{3}$ - socially important indices of quality which are connected with the level of safe movement, the speed of transportation and with indices of quality $-\mathrm{a}_{1} ; \mathrm{a}_{2} ; \mathrm{a}_{3}$ (technical, economical).

We can get the cost of transportation production for consumers $\left(\mathrm{W}_{\mathrm{tkm} \text { ef }}\right)$ in other way too. We must multiply the sum of transportation production amount with the transportation production indices of quality. Indices of quality can be got by one of comparing methods for that $\left(\mathrm{K}_{\mathrm{t}}-\right.$ stretch $)[3]$.

$$
\mathrm{W}_{\mathrm{tkm} \mathrm{ef}}=\mathrm{W}_{\mathrm{tkm}} \mathrm{K}_{\mathrm{t}} \text {. }
$$

The complex of transportation production quality indices shows consumer's needs and the level of their satisfaction.

The multiplication of this complex and the number of transportation production shows the quantity of this complex and the number of transportation production which has consumer's cost. The effective number of transportation production can be shown by the level of satisfaction and its cost of quality and quantity.

Integral indices of transportation production are shown by the relationship between satisfaction of consumers' needs in reality and the sum of the cost of these satisfied needs quantity $\left(\mathrm{K}_{\mathrm{t}}\right)$ :

$$
\mathrm{K}_{\mathrm{n}}=\mathrm{W}_{\mathrm{tkm}} / \Sigma \mathrm{C},
$$

$\Sigma \mathrm{C}$ - social cost for transportation production manufacturing.

Model (3) shows the connection between unbalanced and characteristic social needs. This is the reason why we need to inspect Kt in dynamic' through a bigger number of satisfied consumer's needs. There is a possible situation when Kt grows and the cause of that is the low decrease of speed of cost. In the other situation the cause of that is when the increase of quality is bigger than the increase of quantity.

In all situations there is one question. This question is about the connection level of (3) model indices and their recension for sutisfying social needs. This is the cause why management in organizations is looking after these indices, their connection and final results for society.

\section{Analysis of factors and the method which deter- mines the interaction between the level of transpor- tation services and transportation economical and manufacturial factors}

An effective method for interaction processes is the analysis of range indices and the analysis of factors. We can get a list of indices if organization fixes the other indices which are connected with organization work. This list allows to know which connection between indices is not good for the company. For example, a big number of happenings in transport brings the increase of run. The analysis of aggregate indices gives us ranged information. Finally, elementary comperative work with factual and advisable numbers can give us a real level of standard regime due to inversion range and other varieties.

The analysis of factors is one of powerful research instruments which due to PC can be used for solving management problems in a company:

- constriction of information. The way of constriction is happening due to factors and described information about a process;

- behavior of important and objective relevances in a needed process;

- statistical evaluation between indices and factors on which basis a director can assume an important decision.

- when you are planing the analysis of factors 
you must carefuly look at the connection between indices and quantitative recension of each of these indices. The result of this analysis will be on a statistical base if the quantity of all indices is 3 times bigger than each of these indices [4].

The conclusion about safe movement research is made due to manufacturial and economical factors.

The results of the research which are made by airline organization permit us to think about the quality of models, relevances and tends between manufactural and economical services, factors and the level of safe fly, quality, consumer's cost about transportation products and other costs. We can combine:

- the quality of transportation production and its evolution through coefficient K. This coefficient is very informative, loyal and impressible. The coefficient allows to catch recension in manufactured and economical factors like factors which are connected with a definite level, for example, potential decrease of safe fly. It gives us the conditions of this dangerous action in the first step of incipience.

- Due to $\mathrm{K}_{1}$ we can make a comperative analysis of transportation production quality and quantity of work in dynamics. It is in all kind of planes and in different airline organizations.

- In the research process we accept theoretically important relevance that tendency of unsafe fly is bigger, if factual D1, D2, D3 are tended to be very close and approach normative D1, D2, D3.

- Economical essence of this relevance is proportional to the development of manufactural and economical factors. These factors characterise the relation between the development of materialistic and technical basis (D2) and airline organization work in recourse using area (D3).

- Research into the problem when factual D1, D2, D3 do not support normative D1, D2, D3:

A) Fix the group of manufactural and economical factors which are the cause of decreasing a safe fly condition level. Decreasing of safe fly level happened due to the fly which is not of needed quality, unproportional investments and inefficient use of investment;

B) Provoke the tendency of recension in manufactural and economical rules for transportation production and which are in contradiction with a safe fly process.

C) Fix the way of manufactural and economical rules (recension of dynamic relation between the num- ber of investment and factory cost of transportation production), which can create an optimal situation for increasing a safe fly condition level.

D) Research into relation level between factual and normative D1, D2, D3 due to separate indices degree movement and their analysis. This analysis permits to form factors groups from separate manufactural and economical factors. These groups very vigorously affect dynamical changes in D2 and D3. At the same time these groups affect the transportation production conditions which are formed due to a safe movement level.

E) Effect mechanism of manufactural-economical conditions and factors gives:

- notion about airline organization's materialistic and technical base and the way how to make it stronger (it lets to accept well ground decision for dividing of institutions);

- provides working out of real measures aiming at the improvement of airline services on the basis of flight safety growth.

\section{References}

1. International Standards ISO-9000:2000.

2. Shestakov, V. et all. Engineering and organization foundations of civil aviation on flight safety providing (Инженерно-организационные основы обеспечения безопасности полетов в гражданской авиации). Moscow: Transport, 1987. 174 p. (in Russian).

3. Dissanayake, Y. B.; Pankov, A.; Shestakov, V. Quality control on the basis of entropy determination. Transport, Vol XIX, No 2, Vilnius: Technika, 2004, p 50-55.

4. Pankovs, A.; Ceitlins, V.; Šestakovs V. Transporta kustības drošības nodrošināšanas ekonomiskie aspekti. In: Scientific procedings of Riga Tehnical University. Transport and Engineering. Serija 6, 2002, p. 127-131. 